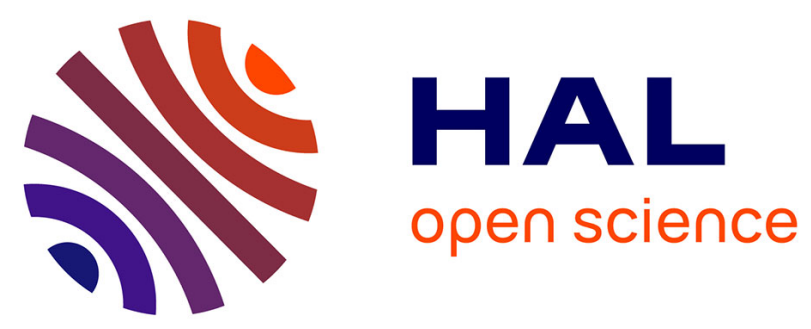

\title{
A Literature-Based Analysis of the Cyber-Physical Systems Under the Lens of Reconfigurability
}

\author{
Napoleone Alessia, Macchi Marco, Pozzetti Alessandro
}

\section{To cite this version:}

Napoleone Alessia, Macchi Marco, Pozzetti Alessandro. A Literature-Based Analysis of the CyberPhysical Systems Under the Lens of Reconfigurability. IFIP International Conference on Advances in Production Management Systems (APMS), Aug 2018, Seoul, South Korea. pp.342-349, 10.1007/9783-319-99704-9_42. hal-02164917

\section{HAL Id: hal-02164917 https://hal.inria.fr/hal-02164917}

Submitted on 25 Jun 2019

HAL is a multi-disciplinary open access archive for the deposit and dissemination of scientific research documents, whether they are published or not. The documents may come from teaching and research institutions in France or abroad, or from public or private research centers.
L'archive ouverte pluridisciplinaire HAL, est destinée au dépôt et à la diffusion de documents scientifiques de niveau recherche, publiés ou non, émanant des établissements d'enseignement et de recherche français ou étrangers, des laboratoires publics ou privés. 


\title{
A literature-based analysis of the Cyber-Physical Systems under the lens of reconfigurability
}

\author{
Napoleone Alessia ${ }^{1[0000-0002-0622-5011]}$, Macchi Marco ${ }^{10000-0003-3078-6051]}$ and Pozzetti \\ Alessandro $^{1[0000-0002-9074-2854]}$ \\ 1 Department of Management, Economics and Industrial Engineering, \\ Politecnico di Milano, Milano, Italy \\ Alessia.napoleonedpolimi.it
}

\begin{abstract}
Cyber-physical systems (CPSs) are an increasingly known set of technologies and applications promising to enable manufacturing firms improving their responsiveness to deal with the unpredictability of market requirements. Indeed, from an operational perspective, responsiveness can be achieved because CPSs are an enabler of the reconfigurability of factories. Reconfigurability is a capability that has been theorized since almost two decades. Therefore, today we can consider such grounded theory as a lens to frame emerging CPS-related knowledge. This paper is an effort to give a contribution in this direction. In particular, starting from the acknowledgement that a relevant characteristic of reconfigurability is modularity, this research proposes a literature-based analysis of the Cyber-Physical Systems of the future smart factory.
\end{abstract}

Keywords: Cyber-Physical System (CPS), Cyber-Physical Production System (CPPS), reconfigurability, modularity, production levels, coordination levels.

\section{Introduction}

The current scenario is challenging manufacturing firms, pushing them to be more and more responsive [1,2]. Indeed, firms need to rearrange quickly their operations in order to pursue ever-changing goals at an affordable cost, producing according to new requirements and technology changes [3,4]. Nowadays, disruptive technological advances are promising to enable firms in meeting these challenges and gain competitive advantage; amongst the technological advances, Cyber-Physical Systems (CPSs) are recognized as the basic units of the future smart factories [5, 6].

According to [7], CPSs are the merger of cyber (electric/electronic) systems with physical things. Using their words, a CPS "helps mechanical systems to perceive the physical world, process these perceptions as data on computers, make calculations, and inform systems to take actions to change process outcomes".

Within manufacturing firms, reconfigurability is nowadays a more and more valuable and desired characteristic. Indeed, over time, a wide base of knowledge has been developed on reconfigurability (see [8]). However, the current digital revolution, which leads to the development of CPSs, can strengthen and renew the achievable reconfigurability (according to literature, CPSs enable the reconfigurability of factories [7]). For 
this reason, this paper investigates on the possibility to interpret the recent CPS-related knowledge under the lens of the grounded reconfigurability theory. Indeed, based on the available literature on reconfigurability, this paper proposes a literature-based analysis of the Cyber-Physical Systems of the future smart factory. To this end, the paper has the following structure. Section 2 adopts a physical perspective. It reviews CPSrelated literature by applying the concept of modularity at different production levels of a firm. Section 3 adopts a cyber-perspective. It reviews CPS-related literature by looking at the roles of modules at different coordination levels. Section 4 summarizes the results of sections 2 and 3 and drives the main conclusions of the paper.

\section{Modularity at different production levels: a physical perspective}

As stressed in reconfigurability-related literature, the capability to reconfigure should be referred to different production levels. More precisely, [9] identified six levels (these were then applied by [10]). However, in real cases, it is often not easy to identify clearly this high number of levels, also because their boundaries are sometimes faded. Thus, for the purpose of this paper, four instead of six levels are considered, in accordance to [11]. These levels are: workstation (correspondent to the individual production phase), system (e.g. cells, lines or production departments), factory and network.

As modularity is one of the core characteristics of reconfigurability [12], it can be applied at the identified production levels. By changing production levels, modules characterizations and functionalities change. To give an example, for [13] the modules of a reconfigurable system at workstation level are the reconfigurable machines. To them, the number of machine configurations can increase the number of system configurations exponentially. Overall, building on modularity as a characteristic of reconfigurability, the functionality of the system at a higher production level can be changed by modifying its modules at a lower production level.

In order to identify relevant literature for the review, we used Scopus as the primary search database. The search consisted of a topic search with two blocks being "cyberphysical system" and "manufacturing". Among the identified papers, the ones referring to either "modularity" or "module" were critically analysed in order to find either explicit or implicit reference to reconfigurability. The following table (Table 1) sorts CPSs-related references according to the production level at which they applied the modularity concept.

Table 1. Production levels at which CPSs-related references applied the modularity concept

\begin{tabular}{|l|l|}
\hline References & Production level \\
\hline$[14,15,16,17]$ & Factory \\
\hline$[18,19,20,21]$ & Factory - System \\
\hline$[22,6,23,24,25]$ & System \\
\hline$[26,27]$ & System - Workstation \\
\hline
\end{tabular}

Overall, the analyzed CPSs-related literature focused on modularity at the four aforementioned production levels. To conclude and synthesize this section we can state that, similarly to what already consolidated in reconfigurability literature, modularity of 
CPSs supports their reconfigurability. Furthermore, within the analyzed literature, some authors were more oriented to characterize systems at a certain production level from a physical point of view; others were more oriented to identify the role of such systems, their functionalities at a certain production level and, therefore, the supported tasks. This last perspective introduces the need to extend the analysis to relationships between modules. This aspect is going to be deepened in the following section.

\section{Roles of modules at different coordination levels: a cyber-perspective}

A relevant property of CPSs is their ability to communicate and interact with each other $[25,23]$. Overall, literature has widely remarked that future factories will be made of modules (CPSs) that, empowered by the knowledge gained through interactions, will be self-responsible and autonomously reacting to changes [21, 28, 29]. Cyber manufacturing systems are interacting and cooperating entities enabled by the Industrial Internet of Things [30].

Nonetheless, there are two other aspects that need to be taken into account, besides the self-responsibility and autonomy. On one hand, the need to achieve systemic goals should be guaranteed; to our concern, the systemic goal is to assure reconfigurability as a capability of a manufacturing firm to be responsive with unpredictable changes of market requirements. On the other hand, the inherent properties of the Cyber-Physical modules lead to a lack of systemic view.

Regarding the need to achieve systemic goals of reconfigurability, according to literature [31,32], reconfiguring a system means changing its functionality (exploiting its convertibility) or modifying its production capacity (exploiting its scalability). Thus, modules within a system (at a certain production level) may need to be changed according to a systemic goal of reconfigurability, i.e. a goal of convertibility or scalability at a higher production level. In addition, independently from the systemic goal, an effective reconfiguration should rely on diagnosability, which allows quick identification of the sources of quality and reliability problems during reconfigurations [3], thus reducing the ramp-up time of reconfigurations. Diagnosability can be seen as an intermediate goal in order to achieve scalability and convertibility [11].

To reach the above stated goals, CPSs are not assuring a systemic view, if they are taken solely as single modules [33]. Indeed, even if interactions allow CPSs to develop some knowledge about other CPSs within a certain production level, they lack of the systemic view required to make optimal decisions to reach systemic goals $[34,5,35$, $36,22,37,38]$. This aspect can be better understood by relying on the interpretation of CPSs as modules with their specific roles at different production levels and, consequently, their own functionalities and supported tasks. In other words, CPSs as modules have a "view" which is restricted to the production level they belong to, as it happens with any complex organization of intelligent resources (endowed with different intelligence).

Therefore, we consider appropriate referring to an additional dimension: the coordination level. Indeed, according to: (i) the systemic goals (of scalability, convertibility 
and diagnosability) and to (ii) the systemic knowledge typically possessed at a higher production level, the Cyber-Physical Modules should be smartly coordinated. To support this statement, we further reviewed papers (obtained through the topic search with "cyber-physical system" and "manufacturing"), by selecting and critically analysing the ones referring to the concept of coordination and its goal. Thus, in the following table (Table 2) we gathered and sorted references that described the coordination of CPSs (at a given production level) made by systems with broader views (at the next higher production level). Thus, in such table, we specified the coordinated levels, jointly with the systemic goals, identified (in the second column of the table) as (i) scalability, (ii) convertibility, (iii) diagnosability or (iv) a systemic optimization.

Table 2. Coordination at different production levels according to CPSs-related references

\begin{tabular}{|l|l|}
\hline Coordinated level [References] & Systemic goal \\
\hline Factory [33] - System [40] - Workstation [42] & Not specified \\
\hline Factory [39] - System [36, 41] & Diagnosability \\
\hline System $[22,14]$ & Scalability \\
\hline System $[34,5,35,23,37,38]$ & Systemic optimization \\
\hline
\end{tabular}

Through literature, coordination requirements for either systemic optimizations or reconfigurability goals are illustrated in the reminder.

\subsection{Coordination requirements for systemic optimizations}

To coordinate the factory level, [33] presented a theoretical framework for a first implementation of an Industrial Internet System (IIS) for CPPS. To them, to achieve coordination of the cyber-physical capabilities of a distributed body of CPSs, it is mandatory having a correct structure and organization of the communication functions.

To coordinate the system level, [34] presented a software system that, aiming at coordinating the different CPSs, uses predictive analysis like data mining combined with a decision support system.

According to [35], a CPS is coordinated through the definition of a global goal of the processing chain, localised goals of the chain components, and interoperability architecture.

By proposing a general architecture for smart manufacturing workshop, [23] stressed that the function modules should work in a collaborative mode. Moreover, all the equipment, hardware, and software should be integrated in a common platform. Eventually, information should be exchanged with a MES in order to make optimal decisions.

For [40], the complexity for defining open-knowledge-driven manufacturing execution system (OKD-MES) is in maintaining awareness of overall system state to avoid disruptive actions as various functions may be requested from a system. They illustrated an approach for designing OKD-MES on top of CPSs that controls robot workstations and conveyor-based transportation system. The OKD-MES is then the coordination system, aware of the overall execution of various functions supported by the CPSs. 
An Engineering Support System for sustainable optimization of automation tasks supervision was proposed by [38]. This leads the control engineer to obtain a supervision and control solution that allows to optimize the performance of the system according to the desired key performance indicators.

To coordinate the workstation level, [42] proposed a vertical cyber physical integration of cognitive robots in manufacturing. In her solution, the cognitive robots are vertically integrated into the manufacturing industry and coordinated with the manufacturing execution system.

\subsection{Coordination requirements for reconfigurability goals}

To coordinate the factory level, [39] designed a proactive intention recognition and action recommendation system designed for cyber-physical industrial environments that is able to recommend actions and generate hints for end users without the need of explicit requests. Its contribution is set in a combined changeover, maintenance, and replacement scenario for production factories (which can be considered as supportive to the diagnosability goal). Thus, such system is capable to coordinate the modules of the production system, and it is coordinated with the ERP.

To coordinate the system level, according to [42], the decentralization gained through the exploitation of CPSs can be successful only by ensuring a constant synchronization with a central system.

For [22], the smart factory (composed of CPSs) should adjust product type and production capacity in real-time. Thus, reconfigurable production lines - capable to reconfigure their process paths and recombine manufacturing units dynamically - should be implemented in the smart factory in order to ensure scalability. A holonic architecture that allows the reconfigurability of manufacturing systems was proposed by [14]. It presupposes the presence of a coordinator holon, capable to request the state of the holons and evaluate the best sequence available processes to comply with the transformation of the product holon using the available resource holon. To them, this allows the development of scalable solutions.

According to [41], "CPS is a new research area that aims to seamlessly integrate computers, sensors, and actuators into an application platform so that application software can easily interact with the physical environment". They developed a middleware, which includes components to help monitor services in a service process, identify the cause of problems when they occur, and perform reconfigurations if necessary (which all support the diagnosability goal). The middleware leads to create some coordination level.

\subsection{Concluding remarks}

From a cyber-perspective, the analysis made in this section confirmed that the CyberPhysical Modules, that have their specific roles (thus functionalities), within a broader system, need to be smartly coordinated. Depending on the production level of reference, 
their coordination requirements change, and the need for a coordinating system, allowing optimizing systemic goals, while positioned at next higher production level, arises.

Overall, three further observations need to be added: (i) a few authors explicitly referred to scalability goals. Those who referred to scalability did not specifically focus on "how" the coordination should allow achieving this goal; (ii) we could not find authors explicitly referring to convertibility goals; (iii) authors were slightly sensitive to diagnosability goals.

Based on these evidences, we can state that CPSs can be related to reconfigurability as systemic goals, nonetheless further research should be done on the relationship between the coordination requirements of modules at a certain production level and such goals.

\section{Conclusions}

This paper represents an effort to exploit the soundness of reconfigurability theory as a solid foundation for interpreting the relatively recent knowledge on Cyber-Physical Systems (CPSs). To this end, the concept of modularity, which is a core characteristic of reconfigurability, has been applied to CPSs. Given the twofold nature of such systems (made of physical and cyber components), two variables, i.e. (i) the production level and (ii) the coordination level have been described in order to provide a literaturebased definition of the Cyber-Physical Modules of the future smart factory.

On the one hand, the physical part of modules changes according to the production level of reference. On the other hand, also the cyber part changes according to coordination level of references. Depending on the production level, modules have different "views", thus different needs for coordination. Summarising, moving from lower to higher levels the modules "view" becomes wider, thus influencing and extending their capability to make autonomous decisions. Moreover, having a restricted view introduces the need at higher production levels to coordinate modules at lower production levels.

Further research could aim at associating CPSs to other core characteristics of reconfigurability: integrability, diagnosability, scalability, convertibility and customization. Particularly, as also observed in section 3.3, further research should be made on the relationship between the coordination requirements of modules at a certain production level and the reconfigurability goals.

\section{References}

1. Koren, Y., Wang, W., Gu, X.: Value creation through design for scalability of reconfigurable manufacturing systems, Int. J. Prod. Res., 55(5), 1227-1242 (2017).

2. Shaik, A. M., Rao, V. V. S. K., Rao, C. S.: Development of modular manufacturing systems - a review, Int. J. Adv. Manuf. Technol., 76(5-8), 789-802 (2015).

3. Koren Y., Shpitalni, M.: Design of reconfigurable manufacturing systems, J. Manuf. Syst., 29(4), 130-141 (2010). 
4. Mehrabi, M. G., Ulsoy, A. G., Koren, Y.: Reconfigurable manufacturing systems : Key to future manufacturing, J. Intell. Manuf., 11, 403-419 (2000).

5. Brettel, M., Friederichsen, N., Keller, M., Rosenberg, M.: How Virtualization, Decentrazliation and Network Building Change the Manufacturing Landscape: An Industry 4.0 Perspective, Int. J. Mech. Aerospace, Ind. Mechatron. Manuf. Eng., 8(1), 37-44 (2014).

6. Penas, O., Plateaux, R., Patalano, S., Hammadi, M.: Multi-scale approach from mechatronic to Cyber-Physical Systems for the design of manufacturing systems, Comput. Ind., 86, 5269 (2017).

7. Trappey, A. J. C., Trappey, C. V., Govindarajan, U. H., Sun, J. J., Chuang, A. C.: A Review of Technology Standards and Patent Portfolios for Enabling Cyber-Physical Systems in Advanced Manufacturing. In: IEEE Access, vol. 4, pp. 7356-7382 (2016).

8. Koren, Y., Heisel, U., Jovane, J., Moriwaki, T., Pritschow, G., Ulsoy, G., Van Brussel, H.: Reconfigurable Manufacturing Systems. In: CIRP Annals--Manufacturing Technology, vol. 48, no. 2. pp. 527-540 (1999).

9. Wiendahl, H. P., ElMaraghy, H. A., Nyhuis, P., Zah, M. F., Wiendahl, H. H., Duffie, N., Brieke, M.: Changeable Manufacturing - Classification, Design and Operation. In: CIRP Ann. - Manuf. Technol., vol. 56, no. 2, pp. 783-809 (2007).

10. Andersen, A. L., Brunoe, T. D., Nielsen, K.: Reconfigurable Manufacturing on Multiple Levels: Literature Review and Research Directions. In: Advances in Production Management Systems: Innovative Production Management Towards Sustainable Growth, pp. 266273 (2015).

11. Napoleone, A., Pozzetti, A., Macchi, M.: A framework to manage reconfigurability in manufacturing, Int. J. Prod. Res., (published online) (2018).

12. Koren, Y.: The rapid responsiveness of RMS, Int. J. Prod. Res., 51(23-24), 6817-6827 (2013).

13. Bi, Z. M., Sherman, Y., Lang, T., Verner, M., Orban, P.: Development of reconfigurable machines, Int. J. Adv. Manuf. Technol., 39(11-12), 1227-1251 (2008).

14. Contreras, J. D., Garcia, J. I., Pastrana, J. D.: Developing of industry 4.0 applications, Int. J. Online Eng., 13(10), 30-47 (2017).

15. Liu Y., Xu, X.: Industry 4.0 and Cloud Manufacturing: A Comparative Analysis, J. Manuf. Sci. Eng., 139(3), 347011-18 (2016).

16. Wang, K.: Intelligent Predictive Maintenance ( IPdM ) system - Industry 4 . 0 scenario, In: WIT Trans. Eng. Sci., vol. 113, pp. 259-268 (2016).

17. Rosenberg, E., Haeusler, M. H., Araullo, R., Gardner, N.: Smart Architecture-Bots and Industry 4.0 Principles for Architecture. In: Proc. 33rd eCAADe Conf., vol. 2, pp. 251-259 (2015).

18. Otto, J., Vogel-Heuser, B., Niggemann, O.: Automatic Parameter Estimation for Reusable Software Components of Modular and Reconfigurable Cyber-Physical Production Systems in the Domain of Discrete Manufacturing. In: IEEE Trans. Ind. Informatics, vol. 14, n. 1, pp. 275-282 (2018).

19. Pereira, A. C., Romero, F.: A review of the meanings and the implications of the Industry 4.0 concept. In: Procedia Manufacturing, vol. 13, pp. 1206-1214 (2017).

20. Ito, Y.: Layout design for flexible machining systems in FCIPS and convertibility to CPS module in smart factory, J. Mach. Eng., 4(17), 5-28 (2017).

21. Monostori, L.: Cyber-physical production systems: Roots, expectations and R\&D challenges. In: Procedia CIRP, vol. 17, pp. 9-13 (2014).

22. Chen, B., Wan, J., Shu, L., Li, P., Mukherjee, M., Yin, B.: Smart Factory of Industry 4.0: Key Technologies, Application Case, and Challenges, In:_ IEEE Access, vol. 6, pp. 65056519 (2017). 
23. Zheng M., Ming, X.: Construction of cyber-physical system-integrated smart manufacturing workshops: A case study in automobile industry, Adv. Mech. Eng., 9(10), 1-17 (2017).

24. Hwang, J. S.: The Fourth Industrial Revolution (Industry 4.0): Intelligent Manufacturing, Engineering, 3(5), 616-630 (2017).

25. Energetics Incorporated, Cyber-Physical Systems : Situation Analysis of Current Trends, Technologies, and Challenges, Natl. Inst. Stand. Technol., p. 67 (2012).

26. Choi, S. H., Jeong, I. B., Kim, J. H., Lee, J. J.: Context generator and behavior translator in a multilayer architecture for a modular development process of cyber-physical robot systems. In: IEEE Trans. Ind. Electron., vol. 61, no. 2, pp. 882-892 (2014).

27. Zhang, Y., Qian, C., Lv, J., Liu, Y.: Agent and Cyber-Physical System Based Self-Organizing and Self-Adaptive Intelligent Shopfloor. In: IEEE Trans. Ind. Informatics, vol. 13, no. 2, pp. 737-747 (2017).

28. Uhlmann E., Geisert, C.: Intelligent production systems in the era of industrie 4 .0-changing mindsets and business models, Journal of Machine Engineering, 17(2), 5-24 (2017).

29. Shamim, S., Cang, S., Yu, H., Li, Y.: Examining the feasibilities of Industry 4.0 for the hospitality sector with the lens of management practice, Energies, 10(4), 499 (2017).

30. Jeschke, S., Brecher, C., Meisen, T., Özdemir, D., Eschert, T.: Industrial Internet of Things and Cyber Manufacturing Systems, In: Industrial Internet of Things, pp. 3-19, 2017.

31. ElMaraghy, H. A.: Flexible and reconfigurable manufacturing systems paradigms, Int. J. Flex. Manuf. Syst., 17(4), 261-276 (2006).

32. Rösiö, C.: Supporting the design of reconfigurable production systems, 130 (2012).

33. Rojas, R. A., Rauch, E., Vidoni, R., Matt, D. T.: Enabling Connectivity of Cyber-physical Production Systems: A Conceptual Framework, Procedia Manuf., 11, 822-829, (2017).

34. Trstenjak, M., Cosic, P.: Process Planning in Industry 4.0 Environment, Procedia Manuf., 11, 1744-1750 (2017).

35. Morgan, J., G. E. O'Donnell, Multi-sensor process analysis and performance characterisation in CNC turning - a cyber physical system approach, Int. J. Adv. Manuf. Technol., 92(14), 855-868 (2017).

36. MPDV, Industry 4.0: MES supports Decentralization, MPDV Mikrolab GmbH, https://www.mpdv.com/uploads/tx_news/NEWS_International_2015_web.pdf, last accessed 2018/07/10.

37. Li, D., Tang, H., Wang, S., Liu, C.: A big data enabled load-balancing control for smart manufacturing of Industry 4.0, Cluster Comput., 20(2), 1855-1864 (2017).

38. Mazzolini, M. Cavadini, F. A. Montalbano, G., Forni, A.: Structured Approach to the Design of Automation Systems through IEC 61499 Standard, Procedia Manuf., 11, 905-913 (2017).

39. Haupert, J., Bergweiler, S., Poller, P., Hauck, C.: IRAR: Smart intention recognition and action recommendation for cyber-physical industry environments. In: Proc. of 2014 Int. Conf. Intell. Environ. IE 2014, pp. 124-131 (2014).

40. Iarovyi, S., Mohammed, W. M., Lobov, A., Ferrer, B. R., Lastra, J. L. M.: Cyber-Physical Systems for Open-Knowledge-Driven Manufacturing Execution Systems. In: Proc. IEEE, vol. 104, no. 5, pp. 1142-1154 (2016).

41. Lin, K. J., Panahi, M.: A real-time service-oriented framework to support sustainable cyberphysical systems. In: IEEE Int. Conf. Ind. Informatics, pp. 15-21 (2010).

42. Valente, A.: Reconfigurable industrial robots - An integrated approach to design the joint and link modules and configure the robot manipulator, in Advances in Reconfigurable Mechanisms and Robots II, vol. 36, pp. 779-794 (2016). 